KUHN, Thomas S. A estrutura das revoluções científicas. 5. ed. São Paulo: Editora Perspectiva S.A, 1997.

\title{
RESENHANDO AS ESTRUTURAS DAS REVOLUC̣̃̃ES CIENTÍFICAS DE THOMAS KUHN
}

Roberta Chiesa Bartelmebs*
*Mestre em Educação em
Ciências pela Fundação
Universidade Federal do Rio
Grande (FURG). Professora
do Ncleo de Estudos em
Epistemologia e Educação em
Ciências (NUEPEC/FURG).
Colaboradora do Núcleo de
Pesquisa e Extensão sobre o
Bebê e a Infância (NUPEBI).

\section{PORQUE AINDA THOMAS KUHN}

Apesar de já se passarem mais de 30 anos da publicação da obra $A$ estrutura das revolucõos científicas, ela permanece atual em termos de discussões epistemológicas e estruturais da constituição das ciências. A importância de qualquer cientista conhecer tal obra se deve ao fato de que ela descaracteriza o mito que se criou em torno das ciências e dos cientistas com o advento da era científica e tecnológica.

Kuhn demonstra que, além de serem construções humanas, as ciências são também, e consequentemente, construções sociais e históricas. Disso resulta uma nova compreensão acerca dos processos científicos, e por que não dizer, de alfabetização científica.

A atualidade da obra é justificada também por seu caráter inovador. Sem pretensões de ser uma obra de referência mundial, Kuhn apenas fez de seu relatório de pesquisas e das suas inquietações um objeto de estudo que cada vez mais cresceu diante de suas pesquisas. Eis um modelo de compreensão da prática da filosofia das ciências: a pesquisa em busca de saberes que desvelem as verdades que se estabelecem sem questionamento. Isso vale para qualquer campo de estudos, seja nas ciências sociais, humanas, naturais ou exatas.

\section{SOBRE THOMAS KUHN}

Kuhn é um físico que, durante seu engajamento no processo de pós-graduação, intrigou-se com algumas afirmações à respeito da ciência e da história da ciência. Como ele mesmo refere-se no prefácio de sua obra, foi durante o envolvimento com o ensino de Física experimental para não cientistas que ele teve contato com a história da ciência. Foi nessa oportunidade que Kuhn percebeu diferenças entre o que dizia a história da ciência e o que ocorria durante as atividades experimentais para o público leigo. 
Foi desse interesse incomum que surgiram os estudos "arqueológicos" na história da ciência de Kuhn. Na maioria das vezes, quando realizamos atividades experimentais para públicos de não cientistas, não nos questionamos sobre a validade de nossos argumentos ou sobre a forma como a ciência é apresentada.

Para Kuhn, o contato com diferentes áreas do conhecimento, como a epistemologia, a psicologia e as ciências naturais e sociais, permitiu um olhar mais atento e mais complexo sobre a história da ciência. E não apenas isto, mas esse contato lhe permitiu compreender como se dá a construção e a validação de uma ciência, bem como sua manutenção e superação. Assim, como o próprio autor defende, sua inserção na história da ciência está mais interessada em processos epistemológicos do que contextuais ou sociais, o que não significa que estes nãos estejam presentes em seus estudos, pois, como veremos adiante, em cada época há um conjunto de saberes que permitem fazer esta ou aquela leitura da realidade à qual estamos submetidos.

\title{
A HISTÓRIA DA CIÊNCIA
}

Um dos objetos de estudos dessa obra de Kuhn é a história da ciência. Para ele, é nessa disciplina que se encontram os detalhes da produção científica de uma determinada comunidade:

\begin{abstract}
(...) a História da Ciência torna-se a disciplina que registra tanto esses aumentos sucessivos como os obstáculos que inibiram sua acumulação. Preocupados com o desenvolvimento cientifico, o historiador parece então ter duas tarefas principais. De um lado deve determinar quando e por quem cada fato, teoria ou lei cientifica contemporânea foi descoberta ou inventada. De outro lado, deve descrever e explicar os amontoados de erros, mitos e superstições que inibiram a acumulação mais rápida dos elementos constituintes do moderno texto científico. (p.20)
\end{abstract}

Essas tarefas do historiador, no entanto, são complexas e remetem a diferentes entendimentos do que seja ciência. Kuhn argumenta que: "Talvez a ciência não se desenvolva pela acumulação de descobertas e invenções individuais ..." (p.21). Assim, quando os historiadores dedicam-se ao estudo de uma concepção ou teoria científica percebem que para a época eram tão científicas quanto as teorias e concepções que temos hoje:

Quanto mais cuidadosamente estudam, digamos, a dinâmica aristotélica, a química flogística ou a termodinâmica calórica, tanto mais certos tornam-se de que, como um todo, as concepções de natureza outrora correntes não eram nem menos cientificas, nem menos o produto de idiossincrasias do que as atualmente em voga. (p.21)

É nesse sentido que podemos perceber o entendimento de ciência para Kuhn. Ao contrário do que sempre vimos nos manuais científicos, a ciência não é o acúmulo gradual de conhecimentos, mas é a complexa relação entre teorias, 
dados e paradigmas. Tampouco a Ciência é neutra. Mesmo em seus métodos, como a observação e a experimentação, ela define de antemão o que é ou não possível de ser realizado: "A observação e a experiência podem e devem restringir drasticamente a extensão das crenças admissíveis, porque de outro modo não haveria ciência. Mas não podem, por si só, determinar um conjunto específico de semelhantes crenças." (p. 23)

Ou seja, a observação é feita sobre aquilo que é possível "ver" dentro de um paradigma. Se tomarmos como exemplo a astronomia, veremos que, para Ptolomeu, em seu Almagesto ${ }^{2}$, a Terra tinha de ser o centro do universo. Isso porque toda a conformação teórica tinha de derivar da perfeição geométrica, produto dos sólidos de Platão. Além disso, a representação do universo estava baseada na teoria de Aristóteles de que o mundo supra lunar era perfeito e imutável e o mundo sub lunar era imperfeito e mutável.

Se nos remetermos a essas concepções teóricas, veremos que de fato o mundo supra lunar aparentemente é perfeito e imutável, uma vez que as estrelas "fixas" não mudam suas posições no céu. Elas surgem e ressurgem periodicamente "no mesmo lugar". Quando surge alguma anomalia, como o movimento de Marte, que parece retrógrado em determinado momento de sua translação, o que vai contra os pressupostos do movimento circular perfeito, adequações são feitas, e o uso de epiciclos retoma a ideia da perfeição e da harmonia do mundo supra lunar.

É nesse sentido também que a ciência normal e o paradigma delimitam aquilo que pode ou não ser "visto" na natureza ou nos fenômenos que submetemos à pesquisa dentro de uma comunidade cientifica.

\section{O CONCEITO DE PARADIGMA}

O conceito de paradigma vai atravessar toda essa obra de Kuhn com um sentido muito específico. Já na introdução, Kuhn apresenta a seguinte definição: "Considero "paradigmas" as realizações científicas universalmente reconhecidas que, durante algum tempo, fornecem problemas e soluções modelares para uma comunidade de praticantes de uma ciência". (p. 13).

Ou seja, o paradigma é um conjunto de saberes e fazeres que garantam a realização de uma pesquisa científica por uma comunidade. O paradigma determina até onde se pode pensar, uma vez que dados e teorias, sempre que aplicados a uma pesquisa, irão confirmar a existência desse paradigma.

Extrapolando a leitura para o campo da educação, podemos pensar que estamos submetidos também a um paradigma, isto é, a uma forma de entender e fazer ciência na educação que leva em consideração um aspecto dos fenômenos de ensino e de aprendizagem. Nosso paradigma atual na educação é o ensino. Todas as pesquisas, todas as dissertações e teses têm alguma relação com esse paradigma. Todos querem melhorar o ensino. Toda a preocupação de nossas últimas produções tem sido a tarefa de ensinar mais e melhor.

Mesmo quando estudamos o outro pólo da relação, a aprendizagem, é 
para garantirmos um melhor ensino. A formação dos profissionais em educação está muito mais interessada na qualidade do ensino do que na aprendizagem. Muito embora também possamos defender que esses processos não sejam separáveis, há uma nítida diferença entre formar para ensinar e formar para possibilitar aprendizagens.

No entanto, no campo da educação, percebemos que existem rupturas e alianças com outras áreas que movem novos entendimentos dessa ciência. Perguntas e dados que não podem mais ser respondidos ou compreendidos pelo paradigma do ensino passam agora a desafiar os cientistas da educação. A isto, Kuhn chama de crise de paradigmas.

Essa crise de paradigmas é a responsável pelas mudanças conceituais e procedimentais dentro de um campo do saber. Ela surge dentro da chamada ciência normal, por meio de anomalias que não se conformam as formas tradicionais de conceber o processo e o produto científico. Conforme Kuhn:

E quando isto ocorre - isto é, quando os membros da profissão não podem mais esquivar-se das anomalias que subvertem a tradição existente da prática científica - então começam as investigações extraordinárias que finalmente conduzem a profissão a um novo conjunto de compromissos, a uma nova base para a prática da ciência. (p. 25)

Ou seja, quando as formas tradicionais de pesquisa já não respondem às necessidades que novos dados ou novos fatos impõem, as investigações extraordinárias permitem o surgimento de novidades na pesquisa e na ciência. Isso conduz a comunidade científica a novas formas de praticar sua ciência.

\section{A CIÊNCIA NORMAL}

Outro conceito específico da obra de Kuhn é o de ciência normal. Para ele, ela se desenvolve junto com a ideia de paradigma, ou seja, podemos compreender que a ciência normal é produto e produtor de um paradigma. Isso fica evidenciado no seguinte trecho:

Invenções de novas teorias não são os únicos acontecimentos científicos que tem um impacto revolucionário sobre os especialistas do setor em que ocorrem. Os compromissos que governam a ciência normal especificam não apenas as espécies de entidades que o universo contém, mas também, implicitamente, aquelas que não contém. (p. 26)

A ciência normal é o estado de uma ciência na qual suas pesquisas e seus resultados são previsíveis, isto é, ela acontece adequando a realidade às teorias e esquemas conceituais que os cientistas aprendem na sua formação profissional. Diante disso, podemos dizer que a comunidade científica sabe como é o mundo, e as pesquisas servem para comprovar ou aperfeiçoar esses saberes. Para Kuhn:

Neste ensaio, "ciência normal" significa a pesquisa firmemente baseada em uma ou mais realizações passadas. Essas realizações são reconhecidas durante algum tempo por alguma comunidade científica específica como proporcionando os fundamentos para sua prática posterior. (p.29) 
Uma metáfora que Kuhn utiliza para a ciência normal é a montagem de quebra-cabeças. Ou seja, a realidade seria uma porção de peças que, ao serem corretamente unidas, nos daria uma visão real de como a natureza ou os fenômenos estudados funcionam. Além disso, quando montamos um quebra-cabeça, em geral já sabemos aonde vamos chegar, isto é, já sabemos qual o produto final que o encaixe das peças vai nos proporcionar ver.

Nisto não há espaço para a novidade. Na ciência normal, não há espaço para o inusitado ou para o inesperado. Assim como na montagem do quebra-cabeça, já se sabe aonde se quer chegar. Se houver um encaixe de peças errado, o que se deverá fazer não é questionar o motivo pelo qual isso ocorreu, mas sim retirá-la e colocá-la no seu devido lugar. À ciência, e ao cientista, caberia a função de encaixar a peça certa no local correto com base nas evidências que as demais peças lhe dão, ou seja, aquilo que já foi feito por outros cientistas anteriormente e que funcionou.

A ciência normal não está preocupada em criar novidades, mas em se especializar naquilo que já está posto pelo paradigma vigente. As experiências não criam novidades (intencionalmente), mas desejam especificar melhor o que já se sabe: "O resultado já é sabido de antemão, o fascínio está em como se vai chegar até ele". (p. 60).

\section{DAS REVOLUÇÕES CIENTÍFICAS: POR QUE COPÉRNICO REVOLUCIONOU?}

Com o avanço da ciência normal, vemos surgir novos problemas e novas questões. Conforme Kuhn: "Mas os problemas extraordinários não surgem gratuitamente. Emergem apenas em ocasiões especiais, geradas pelo avanço da ciência normal". (p 55).

Quando uma anomalia perturba o andamento da pesquisa na ciência normal, surgem novos e reforçados movimentos de adequação dos dados às teorias existentes. Como no já citado caso da astronomia grega, as anomalias eram condicionadas àquilo que se dispunha de conceitos e teorias da época.

Quando uma novidade surgiu no céu, logo se tratou de adequá-la à teoria existente. No entanto, essas anomalias nem sempre são percebidas, uma vez que a ciência normal (como vimos anteriormente) não está preocupada em criar novidades, mas em se especializar naquilo que já está posto pelo paradigma vigente. As experiências não criam novidades (intencionalmente), mas desejam especificar melhor o que já se sabe.

No entanto, as anomalias persistem. Elas podem gerar o que Kuhn chama de crise de paradigma:

De forma muito semelhante (ao que ocorre nas revoluções políticas), as revoluções científicas iniciam-se com um sentimento crescente, também seguidamente restrito a uma pequena subdivisão da comunidade científica, de que o paradigma existente deixou de funcionar adequadamente na exploração de um aspecto da natureza, cuja exploração fora 
anteriormente dirigida pelo paradigma. [...] o sentimento de funcionamento defeituoso, que pode levar à crise, é um pré-requisito para a revolução. (p. 126).

Portanto, as anomalias provocam desajustes nas teorias vigentes, o que leva a um sentimento de "funcionamento defeituoso" da teoria que promove uma crise no paradigma vigente e serve de pré-requisito à revolução.

Retomando o caso da astronomia, quando Galileu aponta a luneta para a Lua, percebe que esta não se parece nem um pouco com uma esfera perfeita, conforme julgaram os aristotélicos. Das suas observações criteriosamente anotadas em Sidereus Nuncius ${ }^{3}$, Galileu descreve que:

Do seu exame (da Lua) muitas vezes repetidos, deduzimos que podemos discernir com certeza que a superfície da Lua não é perfeitamente polida, uniforme e exatamente esférica, como um exército de filósofos acreditou, acerca dela e de outros corpos celestes [...] (2010, p.156)

Nesse momento, Galileu anuncia uma anomalia a qual não pode se encaixar nas teorias vigentes e no paradigma da época. $\mathrm{O}$ fato de haver montanhas, crateras e irregularidades na superfície da Lua contrariava e muito as ideias aristotélicas acerca da natureza dos corpos celestes.

No entanto, conforme assegura Kuhn, "A transição de um paradigma em crise para um novo, do qual pode surgir uma nova tradição e ciência normal, está longe de ser um processo cumulativo obtido através de uma articulação do velho paradigma" (p. 116)

Aqui é preciso fazer um esclarecimento. Antes de Galileu utilizar a luneta para observar a Lua e os objetos celestes com maior precisão, houve outro astrônomo que possibilitou essa "abertura" ao inusitado e à novidade. Podemos dizer mesmo que através da resistência de um grupo de astrônomos foi possível causar crise no paradigma vigente e permitir que se instalasse uma revolução.

Esse astrônomo é Nicolau Copérnico. Ele é tido como o responsável por colocar a Terra em movimento. Para a época, e para o paradigma vigente, era impossível conceber que a Terra se movia, uma vez que isso não era "observável" no cotidiano. Caso a Terra se movesse, pássaros, pessoas, objetos deveriam "sair" da Terra, ou seja, seriam deixados para trás.

Esses eram os entendimentos permitidos pelo paradigma vigente. $\mathrm{E}$ como os dados empíricos, da natureza das observações e experimentos feitos até então, não contradiziam essa teoria, ela era tida como verdadeira e científica.

No entanto, Copérnico, em sua obra De revolutionibus orbium coelestium ${ }^{4}$, coloca a Terra em movimento e a retira do centro do universo. No entanto, esse feito não é apenas um simples deslocamento de posições em mapas ilustrativos do universo. Muito além disso, trata-se de conceber novas concepções para as ideias até então desenvolvidas sobre todo o universo, conforme afirma Kuhn:

[...] a inovação de Copérnico não consistiu simplesmente em movimentar a Terra. Era antes uma maneira completamente nova de encarar os problemas da Física e da Astronomia, 
que necessariamente modificava o sentido das expressões "Terra" e "movimento". Sem tais modificações, o conceito de Terra em movimento era uma loucura. (p. 190)

Portanto, Copérnico é, de fato, responsável por uma revolução tanto na Física quanto na Astronomia. No entanto, é ilusão pensar que essa revolução instalou-se e foi bem sucedida em pouco tempo. Copérnico não foi aceito durante quase um século, haja vista que alguns adeptos de suas teorias foram colocados à duras provas pelos "cientistas" da época da Inquisição. Giordano Bruno e Galileu são exemplos claros da morosidade e da complexidade que compõem mudanças de paradigmas.

\section{PARA ENTENDER A NATUREZA DA CIÊNCIA, ENTÃO!}

Chama atenção, logo no prefácio desse texto de Kuhn, a seguinte colocação:

A pesquisa eficaz raramente começa antes que uma comunidade cientifica pense ter adquirido respostas seguras para perguntas como: quais são as entidades fundamentais que compõem o universo? Como interagem essas entidades umas com as outras e com os sentidos? Que questões podem ser legitimamente feitas a respeito de tais entidades e que técnicas podem ser empregadas na busca de soluções? (p.23)

Percebemos que teorias sempre sustentam as buscas científicas de uma comunidade de pesquisadores. Nunca os dados serão analisados de forma neutra e isenta de teorias. Na tentativa de explicar este ou aquele fenômeno, estamos sempre propensos a fazer uso das teorias que nos constituem.

Nosso olhar nunca é isento de julgamentos. Somos constituídos do paradigma vigente. Embora isso limite nossa visão para o novo (conforme vimos na ciência normal), é possível que anomalias surjam em nossas pesquisas. Nosso primeiro movimento certamente será o de adequá-las o mais rápido possível àquilo que temos como verdade científica. Caso isso não se dê, ou seja, caso as anomalias persistam, o caminho certamente será o da mudança.

Só que esse caminho não se dá de forma isolada, nem se dará de maneira imediata. Isso pode ser visto claramente no campo da educação. Diversos pequenos grupos à margem do paradigma vigente buscam soluções para problemas nas teorias atuais.

Como falamos anteriormente, irregularidades estão ocorrendo. Por melhor que sejam os métodos de ensino aplicados pelas melhores didáticas, as aprendizagens não ocorrem sempre, tampouco da maneira esperada.

É possível que dessas anomalias os pequenos grupos de cientistas da educação consigam mobilizar novas possibilidades, que o inusitado e o criativo surjam e demonstrem novas possibilidades de compreensão para fazer pesquisas e desenvolver estudos na área da educação. 


\section{NOTAS}

${ }^{1} \mathrm{O}$ Almagesto (que significa $\mathrm{O}$ grande livro) é a publicação magna de Cláudio Ptolomeu. Nela, o autor pretendeu reunir todo o conhecimento da humanidade sobre a astronomia.

2 Sidereus Nuncius, ou O mensageiro das estrelas, é a publicação na qual Galileu inicialmente apresenta as observações feitas com o auxílio do telescópio, instrumento por ele aperfeiçoado. Nessa obra, Galileu dedica-se a relatar suas observações acerca da Lua, de Júpiter e de suas luas.

${ }^{3}$ De revolutionibus orbium coelestium, ou Da revolução das esferas celestes, foi publicado no ano da morte de Copérnico. Nessa obra, o autor faz uma série de apontamentos sobre a Terra, retirando-a do centro do universo e colocando-a em movimento com os demais planetas. Além disso, ele faz referências às estações do ano e aos equinócios, desenvolvendo explicações para tais fenômenos baseado nas evidências empíricas e matemáticas de que dispunha.

\section{REFERÊNCIAS BIBLIOGRÁFICAS:}

GALILEI, Galileu. Sidereus Nuncius: O mensageiro das estrelas. $2^{\mathrm{a}}$ Ed. Fundação Calouste Gulbenkian: Lisboa, 2010.

KUHN, Thomas S. A estrutura das revoluções cientificas. 5. ed. São Paulo: Editora Perspectiva S.A, 1997.

Data do Recebimento: 23/10/2011

Data de Aprovação: 24/12/2011

Data da Versão Final: $07 / 03 / 2012$ 